\title{
Comparison of the methods for platelet rich plasma preparation in horses
}

\author{
Eun-bee Lee, Jung-Won Kim and Jong-pil Seo ${ }^{*}$
}

\begin{abstract}
Platelet rich plasma (PRP) is popularly used in the horse industry to enhance regeneration of tissue injury that has limitation of blood supply. This study aimed to compare the methods for platelet rich plasma preparation since they has not been established yet. Blood was collected from six horses and platelets were concentrated by three different methods (2-step centrifugation, separated centrifugation and separated centrifugation using histopaque). Concentrated blood was analyzed using Advia hematology systems. In the result, separated centrifugation with histopaque showed the significantly lower number of red blood cells than other groups. The 2-step centrifugation showed the significantly higher number of white blood cells than other groups, while it contained the highest concentration of red blood cells among three groups. In the 2-step centrifugation, separated centrifugation and separated centrifugation with histopaque, platelets were concentrated 4.5, 5.3 and 5.6 times, respectively. And no significant difference of the platelet concentration between the three groups was found. This study demonstrated that separated centrifugation using histopaque was the best method for platelet rich plasma preparation because of the proper amount of platelets and the separation of red blood cells from platelet rich plasma.
\end{abstract}

Keywords: Platelet rich plasma, Red blood cells, White blood cells, Horse

\section{Introduction}

Platelet rich plasma (PRP) is the blood plasma which contains a high concentration of platelets. Recently, PRP is largely used in the treatment of equine musculoskeletal, soft tissue, skin injuries [1, 2]. It includes $\alpha$-granules that secrete the growth factors, including platelet-derived growth factor (PDGF), transforming growth factor beta (TGF- $\beta$ ) and vascular endothelial growth factor (VEGF) [3-5]. The growth factors help the migration of the cells and the regeneration of blood vessels, ligaments, tendons, bones and skin [1, 6]. In horses, there are 100,000-350,000 platelets/ul in the blood and platelet rich plasma should contain three times to five times of platelets [7]. However, there is no establishment of the methods for platelet rich plasma preparation [8]. Therefore, the purpose of this study is a comparison of the three different methods for platelet rich plasma preparation.

\footnotetext{
* Correspondence: jpseo@jejunu.ac.kr

College of Veterinary Medicine and Veterinary Medical Research Institute, Jeju National University, Jeju-City, Jejudo 63243, Republic of Korea
}

\section{Materials and methods}

Six horses were used in this study (two of Thoroughbred and four of Halla horses; two males and four females; mean age, 8 years; mean weight, $340 \mathrm{~kg}$ ). Blood was collected from jugular vein using $16 \mathrm{G}$ catheter into acid citrate dextrose A (ACD-A) coated syringes. Complete blood count was performed by Advia hematology systems.

In a 2-step centrifugation method, blood was centrifuged at $200 \mathrm{~g}$ for $15 \mathrm{~min}$. A layer of platelet rich plasma and white blood cells were collected. The suspension was centrifuged again at $900 \mathrm{~g}$ for $15 \mathrm{~min}$. The supernatant was discarded and $1.5 \mathrm{ml}$ of platelet rich plasma was collected and analyzed by Advia hematology systems. In a separated centrifugation method, blood was centrifuged at $200 \mathrm{~g}$ for $15 \mathrm{~min}$ and plasma was collected. Residual white blood cells and red blood cells were collected in a different tube. Plasma was centrifuged at $900 \mathrm{~g}$ for $15 \mathrm{~min}$, the supernatant was discarded and $1 \mathrm{ml}$ of plasma was collected. Residual blood cells were centrifuged at $200 \mathrm{~g}$ for $15 \mathrm{~min}$ and the supernatant was collected. Collected plasma and white blood cells were mixed together, then complete blood was counted. In a separated centrifugation using histopaque (Histopaque ${ }^{\circ}$-1119, Sigma, St. Louis, USA) method, blood

(C) The Author(s). 2018 Open Access This article is distributed under the terms of the Creative Commons Attribution 4.0 International License (http://creativecommons.org/licenses/by/4.0/), which permits unrestricted use, distribution, and 
was centrifuged at $200 \mathrm{~g}$ for $15 \mathrm{~min}$ and plasma was collected and then centrifuged again at $900 \mathrm{~g}$ for $15 \mathrm{~min}$. The supernatant was discarded and collected the plasma. Residual blood cells were collected into a different tube and mixed with PBS (1:1). Histopaque was added into the tube and the suspension was centrifuged at $400 \mathrm{~g}$ for $30 \mathrm{~min}$. White blood cells were separated and washed with PBS, then centrifuged again at $200 \mathrm{~g}$ for $10 \mathrm{~min}$. PBS was removed and white blood cells were added into the plasma tube. Complete blood count was performed (Fig. 1). All the
A

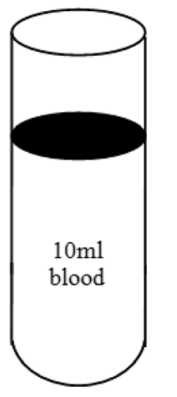

B

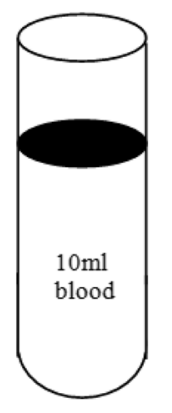

C

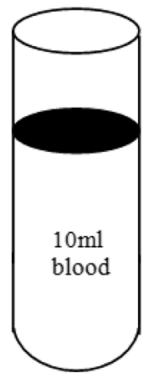

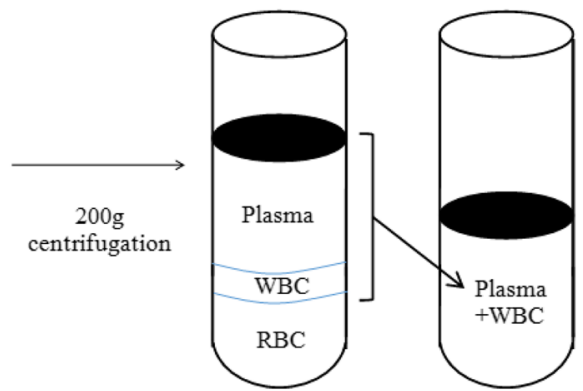

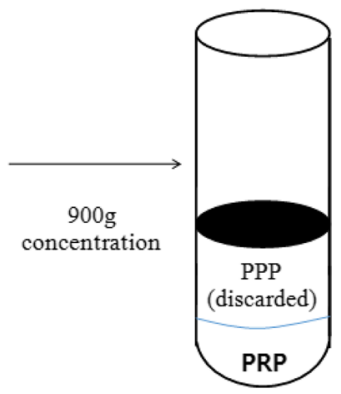

2-step centrifugation
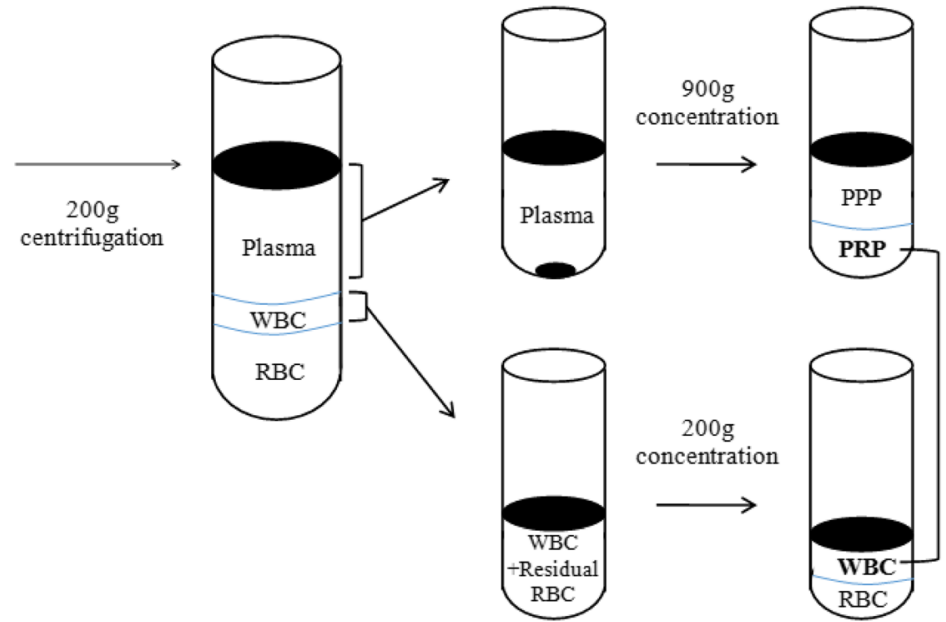

Separated centrifugation
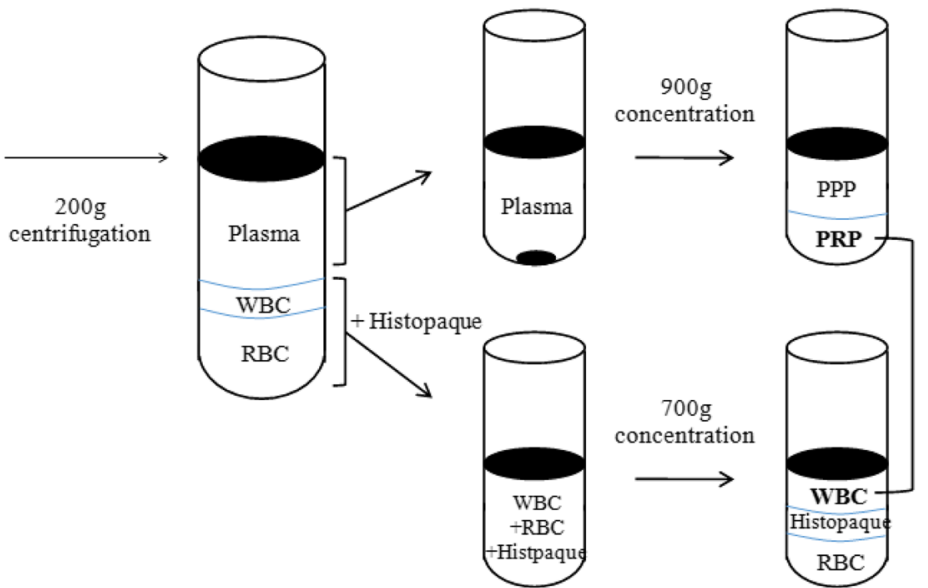

Separated centrifugation with histopaque

Fig. 1 Summary of the methods for platelet rich plasma preparation. a, 2-step centrifugation. b Separated centrifugation. c Separated centrifugation with histopaque 
data obtained was analyzed by a statistical software (SPSS Inc., IBM, USA) using non-parametric Mann-Whitney (statistical significance was considered at $P<0.05$ ) and Kruskal-Wallis tests (statistical significance was considered at $P<0.017$ ).

\section{Results}

Red blood cells were significantly lower in the method of separated centrifugation using histopaque (mean $0.09 \pm$ $0.05 \times 10^{6} / \mathrm{ul}$ ) and significantly higher in the 2-step centrifugation method (mean $8.50 \pm 2.31 \times 10^{6} / \mathrm{ul}$ ) than in other groups. The significantly higher number of white blood cells was shown in the 2-step centrifugation (mean 35.20 $\pm 3.65 \times 10^{3} / \mathrm{ul}$ ) and the lowest number was shown with separated centrifugation with histopaque method (mean $12.53 \pm 2.59 \times 10^{3} / \mathrm{ul}$ ). However, a significant difference of the number of white blood cells between the separated centrifugation and separated centrifugation with histopaque was not found. The platelets were the most concentrated with separated centrifugation with histopaque method. In the 2-step centrifugation, separated centrifugation and separated centrifugation with histopaque, platelets were concentrated 4.5, 5.3 and 5.6 times, respectively. However, no significant difference of the platelet concentration between the three groups was found (Table 1).

\section{Discussion}

In a recent study, platelet rich plasma has been thought to take a therapeutic effect in the aspect of not only platelets but also red blood cells and white blood cells [9]. Red blood cells and white blood cells have been identified to have important roles in immune-mediated response [9]. Therefore, regulating the amount of blood cells was important in this study. Since red blood cells increased immune-mediated factors such as interleukin1 and TGF- $\alpha$, it is important to reduce the amount of red blood cells during preparation of platelet rich plasma [6]. Also, it was demonstrated that immune-mediated factors were increased when there were high concentration of red blood cells in platelet rich plasma which have the low number of white blood cells [6]. The efforts to reduce red blood cells were conducted by using single or double centrifugation [10] and difference of time and the gravitational force of centrifugation [11]. In this study, separated centrifugation with histopaque showed the significantly lower number of red blood cells than the 2-step centrifugation and separated centrifugation. This is because histopaque separated the layer of white blood cells from the layer of red blood cells.

The necessity of white blood cells in platelet rich plasma is still controversial. McCarrel $\mathrm{T}$ et al. observed that white blood cells and corticosteroids were effective in the treatment of chronic lateral epicondylitis in horse [12]. Also, platelet rich plasma, including white blood cells except neutrophils had an effect on anterior cruciate ligament fibroblast [13]. Therefore, we had effort to retain white blood cells in platelet rich plasma. However, there are some adverse effects when white blood cells

Table 1 Results of platelet rich plasma analysis

\begin{tabular}{|c|c|c|c|c|c|c|c|c|c|c|c|c|c|}
\hline \multicolumn{2}{|c|}{ Horse } & \multicolumn{4}{|l|}{$\mathrm{RBC}$} & \multicolumn{4}{|l|}{ WBC } & \multirow{2}{*}{\multicolumn{4}{|c|}{ Platelet }} \\
\hline & & & & & & & & & & & & & \\
\hline 1 & $\begin{array}{l}\text { Halla } \\
\text { Female } \\
13 \text { yrs }\end{array}$ & $\begin{array}{l}W^{b, c} \\
6.96\end{array}$ & $\begin{array}{c}A^{b, c} \\
9.03\end{array}$ & $\begin{array}{l}B^{w, a, b} \\
2.51\end{array}$ & $\frac{C^{w, a, b, c}}{0.14}$ & $\begin{array}{l}W^{a, b, c} c \\
7.04\end{array}$ & $\begin{array}{l}A^{w, b, c} \\
36.56\end{array}$ & $\frac{B^{w, a}}{14.85}$ & $\frac{C^{w, a}}{17.06}$ & $\begin{array}{l}W^{a, b, b}, c \\
79\end{array}$ & $\frac{A^{W}}{368}$ & $\begin{array}{c}\mathrm{B}^{\mathrm{W}} \\
556\end{array}$ & $\frac{C^{w}}{605}$ \\
\hline 2 & $\begin{array}{l}\text { Halla } \\
\text { Male } \\
7 \text { yrs }\end{array}$ & 7.07 & 10.82 & 4.15 & 0.11 & 5.94 & 33.25 & 18.55 & 10.69 & 71 & 274 & 439 & 380 \\
\hline 3 & $\begin{array}{l}\text { TB } \\
\text { Female } \\
4 \text { yrs }\end{array}$ & 11.26 & 11.56 & 4.65 & 0.12 & 8.88 & 34.77 & 19.2 & 13.5 & 104 & 503 & 680 & 650 \\
\hline 4 & $\begin{array}{l}\text { TB } \\
\text { Female } \\
4 \text { yrs }\end{array}$ & 7.76 & 6.45 & 2.46 & 0.03 & 7.8 & 34.1 & 21.3 & 13 & 106 & 602 & 427 & 629 \\
\hline 5 & $\begin{array}{l}\text { Halla } \\
\text { Male } \\
7 \text { yrs }\end{array}$ & 6.92 & 6.57 & 2 & 0.02 & 7.9 & 41.6 & 12 & 10.7 & 133 & 494 & 543 & 499 \\
\hline 6 & $\begin{array}{l}\text { Halla } \\
\text { Female } \\
13 \text { yrs }\end{array}$ & 6.61 & 6.57 & 4.56 & 0.13 & 7.97 & 30.89 & 22.72 & 10.25 & 118 & 497 & 610 & 652 \\
\hline \multicolumn{2}{|c|}{ Mean } & 7.76 & 8.50 & 3.39 & 0.09 & 7.59 & 35.20 & 18.10 & 12.53 & 101.83 & 456.33 & 542.50 & 569.17 \\
\hline \multicolumn{2}{|c|}{ SD } & 1.75 & 2.31 & 1.19 & 0.05 & 1.00 & 3.65 & 4.02 & 2.59 & 23.35 & 116.20 & 97.67 & 108.60 \\
\hline
\end{tabular}

A 2-setp centrifugation, $B$ Separated centrifugation, $C$ Separated centrifugation with histopaque, $T B$ Thoroughbred, $W$ Whole blood, $R B C$ Red blood cell, WBC White blood cell, w,a,b,c Different letters represent significant differences between groups ( $P$-value: W vs. A, B, C, Mann-Whitney test, $P<0.05 ; A$ vs. B vs. $C$, Kruskal-Wallis test, $P<0.017)$ 
are concentrated [12]. Immune-mediated factors such as interlukin-1 and TGF- $\alpha$ could be increased because of concentrated neutrophils [11] and platelet rich plasma, including a high concentration of white blood cells decreased synthesis of extracellular matrix [9]. In this study, white blood cells were significantly higher in the 2-step centrifugation method than other groups. The lowest number of white blood cells was observed with the method of separated centrifugation using histropaque but not significantly different with the separated centrifugation. This is may be due to loss of white blood cells during washing procedure.

Different methods for preparation of platelet rich plasma has been developed $[6,7,9,13]$. The proper number of platelets of platelet rich plasma was three to five times higher than whole blood [6]. We prepared platelet rich plasma with the proper number of platelets, since the concentration of platelets in 2-step centrifugation, separated centrifugation and separated centrifugation with histopaque method was 4.5, 5.3 and 5.6 times respectively, with no significant difference.

\section{Conclusion}

The purpose of this study was comparing the methods for platelet rich plasma preparation to ascertain the most appropriate method. We intended to reduce red blood cells and to preserve white blood cells during the process of platelet rich plasma. The method of using histopaque was considered the most appropriate since platelets were concentrated while red blood cells were removed the most and white blood cells were included.

\section{Acknowledgments}

This research was supported by the Basic Science Research Program through the National Research Foundation of Korea (NRF) funded by the Ministry of Education, Republic of Korea. (NRF-2017R1C1B1006030).

\section{Funding}

This research was supported by the Basic Science Research Program through the National Research Foundation of Korea (NRF) funded by the Ministry of Education, Republic of Korea.

\section{Availability of data and materials}

The data generated or analyzed during the current study are available from the corresponding author on reasonable request.

\section{Authors' contributions}

JWK performed the experiments, analyzed the results. EBL participated in analysis of results, and was a major contributor in writing the manuscript. JPS designed the experiments and revised the manuscript. All authors read and approved the final manuscript.

\section{Ethics approval}

The experimental procedure and methods were approved by the Experimental Animal Committee of Veterinary Medicine of Jeju National University, Jeju, Republic of Korea.

\section{Competing interests}

The authors declare that they have no competing interests.

\section{Publisher's Note}

Springer Nature remains neutral with regard to jurisdictional claims in published maps and institutional affiliations.

Received: 26 April 2018 Accepted: 6 August 2018

Published online: 18 August 2018

References

1. Hessel LN, Bosch G, van Weeren PR, lonita JC. Equine autologous platelet concentrates: comparative study between different available systems. Equine Vet J. 2015;47:319-25.

2. Textor JA, Norris JW, Tablin F. Effects of preparation method, shear force, and exposure to collagen on release of growth factors from equine platelet-rich plasma. Am J Vet Res. 2011;72:271-8.

3. Argüelles D, Carmona JU, Pastor J, Iborra A, Viñals L, Martínez P, Bach E, Prades M. Evaluation of single and double centrifugation tube methods for concentrating equine platelets. Res Vet Sci. 2006;81:237-45.

4. Fontenot RL, Sink CA, Werre SR, Weinstein NM, Dahlgren LA. Simple tube centrifugation for processing platelet-rich plasma in the horse. Can Vet J. 2012;53:1266-72.

5. Rutkowski JL, Thomas JM, Bering CL, Speicher JL, Radio NM, Smith DM, Johnson DA. Analysis of a rapid, simple, and inexpensive technique used to obtain platelet-rich plasma for use in clinical practice. J Oral Implantol. 2008; 34:25-33.

6. Carr BJ, Canapp SO Jr, Mason DR, Cox C, Hess T. Canine platelet-rich plasma systems: a prospective analysis. Front Vet Sci. 2016;2:73.

7. Maia L, Souza MV, Ribeiro Jr BS, J.l., de Oliveira AC, Silveira Alves GE, dos Anjos Benjamin L, Robaina Sancler Silvaa YF, Zandi BM, do Carmo Lopes Moreira J. Platelet-rich plasma in the treatment of induced tendinopathy in horses: histologic evaluation. J Equine Vet Sci 2009;29:618-626.

8. Dohan Ehrenfest DM, Rasmusson L, Albrektsson T. Classification of platelet concentrates: from pure platelet-rich plasma (P-PRP) to leucocyte - and platelet-rich fibrin (L-PRF). Trends Biotechnol. 2009;27:158-67.

9. Boswell SG, Schnabel LV, Mohammed HO, Sundman EA, Minas T, Fortier LA. Increasing platelet concentrations in leukocyte-reduced platelet-rich plasma decrease collagen genesynthesis in tendons. Am J Sports Med. 2014;42:42-9.

10. Perez AG, Lana JF, Rodrigues AA, Luzo AC, Belangero WD, Santana MH. Relevant aspects of centrifugation step in the preparation of platelet-rich plasma. ISRN Hematol. 2014;2014:176060.

11. Sundman EA, Cole BJ, Fortier LA. Growth factor and catabolic cytokine concentrations are influenced by the cellular composition of platelet-rich plasma. Am J Sports Med. 2011;39:2135-40.

12. McCarrel T, Fortier $L$. Temporal growth factor release from platelet-rich plasma, trehalose lyophilized platelets, and bone marrow aspirate and their effect on tendon and ligament gene expression. J Orthop Res. 2009;27: $1033-42$.

13. Yoshida R, Murray MM. Peripheral blood mononuclear cells enhance the anabolic effects of platelet-rich plasma on anteriorcruciate ligament fibroblasts. J Orthop Res. 2013;31:29-34
Ready to submit your research? Choose BMC and benefit from:
- fast, convenient online submission
- thorough peer review by experienced researchers in your field
- rapid publication on acceptance
- support for research data, including large and complex data types
- gold Open Access which fosters wider collaboration and increased citations
- maximum visibility for your research: over $100 \mathrm{M}$ website views per year
At $\mathrm{BMC}$, research is always in progress.
Learn more biomedcentral.com/submission 